\title{
Comparison of the Antimicrobial Effects of Silver Nanoparticles Hlone and In Combination with Zataria multiflora Extract On Some Gram-Positive and Gram- Neqative Bacteria
}

\author{
Shirin Sheikholeslami (MSc) \\ Department of Microbiology, Faculty of \\ Advanced Sciences \& Technology, Islamic \\ Azad University, Pharmaceutical Sciences \\ Branch (IAUPS), Young Researchers and \\ Elite Club, Tehran, Iran \\ Seyyed Mahdi Rezayat (PhD) \\ Department of Pharmacology and \\ Toxicology, Faculty of Pharmacy, Islamic \\ Azad University, Pharmaceutical Sciences \\ Branch (IAUPS), Tehran, Iran \\ Seyyed Reza Hosseini Doust (PhD) \\ Department of Microbiology, Faculty of \\ Advanced Sciences \& Technology, Islamic \\ Azad University, Pharmaceutical Sciences \\ Branch (IAUPS), Tehran, Iran \\ Hamid Reza Ahmadi Ashtiani (PhD) \\ Department of Basic Sciences, Faculty of \\ Pharmacy, Islamic Azad University, \\ Pharmaceutical Sciences Branch (IAUPS), \\ Tehran, Iran \\ Corresponding author: Hamid Reza Ahmadi \\ Ashtiani \\ E-mail: ahmadihr@yahoo.com \\ Tell: +98(21) 22602059 \\ Address: Department of Basic Sciences, \\ Faculty of Pharmacy, Pharmaceutical Sciences \\ Branch, Islamic Azad University, Tehran -Iran \\ (IAUPS).
}

Received : 17 Jun 2014

Revised: 03 Feb 2015

Accepted: 01 Mar 2015

\begin{abstract}
Background and Objective: The spread of drug resistance in bacteria have prompted researchers to seek suitable alternative for antimicrobial drugs among various medicinal plants and nanoparticles. The aim of this study was to evaluate the effect of silver nanoparticles alone and in combination with methanol extract of Zataria multiflora on five Gram-positive and Gram-negative bacteria.

Methods: Different concentrations of the nanoparticles and extract alone or in combination with each other were tested against the bacteria, using well diffusion method. Three concentration levels (lowest, average and highest) were prepared form the nanoparticles and the extract for the combination, and finally nine different combinations were prepared.

Results: The extract and nanoparticles showed inhibitory effects against all the tested bacteria. The maximum diameter of growth inhibition zone in the presence of the extract and nanoparticles were observed in Streptococcus pyogenes $(35.6 \mathrm{~mm})$ and methicillinresistant Staphylococcus aureus $(20.6 \mathrm{~mm})$, respectively. The maximum diameter of growth inhibition zone for the combination was measured in S. pyogenes (31mm).

Conclusion: The combination of low concentrations of the plant extract and nanoparticles are more effective against bacteria, but the combination of their high concentrations reduce the antibacterial effects in some cases.

Keywords: Silver Nanoparticles; Zataria Multiflora; Antibacterial Effect; Gram-Positive Bacteria; Gram-Negative Bacteria.
\end{abstract}




\section{INTRODUCTION}

There is a wide spectrum of diseases that are caused by Staphylococcus aureus, ranging from mild skin infections to life-threatening necrotizing pneumonia (1). Methicillinresistant $S$. aureus is also one of the main causes of nosocomial and community-acquired infections, which has become multi-resistant to a wide range of antibiotics. Today, a limited number of antibiotics such as vancomycin are available against this bacterium $(1,2) . S$. epidermidis is a normal skin flora that may sometimes cause infections by biofilm formation. It is also the most important and abundant bacterial specie, responsible for nosocomial blood infections (3). Streptococcus pyogenes is a Gram-positive bacterial pathogen that colonize the skin and throat. These bacteria are the most common cause of pharyngitis, scarlet fever, impetigo and sometime life-threatening infections such as necrotizing fasciitis, in which the bacteria quickly penetrates into deep soft tissues (4).

Pseudomonas aeruginosa is an opportunistic pathogen that can cause serious lifethreatening infections in immunocompromised patients, including patients with cancer, cystic fibrosis and burns (5). This bacterium is responsible for about $10 \%$ of all nosocomial infections. The increasing resistance of these bacteria to antibiotics causes serious problems in treatment and control of infections among burn patients (6). Development of nanotechnology in the past decade has created opportunities for the discovery of metallic nanoparticles' antibacterial effects (7). Silver nanoparticles size ranges from 1 to $100 \mathrm{~nm}$ and their application against infections is increasing, so that these nanoparticles are widely used in medicine to combat microbes (8). Zataria multiflora is a medicinal herb with antimicrobial properties, belonging to the genus Zataria. Thymol and carvacrol are phenolic compounds and the most significant antimicrobial active chemical composition of this plant that can be found in different amount in various parts of Zataria multiflora, including leaves, flowers and roots. P-cymene is a non-phenolic compound with antimicrobial properties and another main component of this plant (9). The increasing spread of antibiotic-resistant bacteria is one of the problems faced by physicians. It is also the reason for the continuous decline in the number of effective antibiotics available for treating these infections. Therefore, it is necessary to find new treatment methods and novel drugs.

\section{MATERIAL AND METHODS}

In this study, the antibacterial effects of Zataria multiflora extract and silver nanoparticles were assessed and the effect of their combination was compared with each of them. Well diffusion method was used to evaluate the antimicrobial effect. Colloidal solutions of silver nanoparticles with brand name of LNP-CS was purchased from the Lotus Nanochemistry Company. The average particle size was $40 \mathrm{~nm}$, which were chemically synthesized with concentration of $8000 \mu \mathrm{g} / \mathrm{ml}$. Dried Zataria multiflora plant was purchased and its scientific name was identified in the herbarium of Faculty of Pharmacy, Tehran University of Medical Sciences and finally classified under the number PMP-404. The plant was powdered and then 100 grams of the powder was weighed and then extraction was done using methanol and Percolation method. The obtained extract was concentrated by vacuum distillation and then kept in colored glass containers in a cool dry place until the time of experiment (10). Pure Gram-positive and Gram-negative bacterial cultures were used in this study, which were previously purchased from the collection center of fungi and industrial bacteria in Iran.

\section{Staphylococcus aureus ATCC25923}

2. Methicillin-resistant Staphylococcus aureus (MRSA) ATCC33591

\section{Staphylococcus epidermidis ATCC14990}

4. Streptococcus pyogenes ATCC19615

5. Pseudomonas aeruginosa ATCC27853

First, 0.5 McFarland bacterial suspension was prepared in sterile normal saline and then culture was done by sterile swabs on Mueller Hinton agar in three directions. Wells with a diameter of $6 \mathrm{~mm}$ were created on the culture medium. To determine the antimicrobial effect of the extract, $100 \mathrm{mg}$ of the plant extract was dissolved with $1 \mathrm{ml} 10 \%$ DMSO as solvent and then serial dilutions of 1.2, 1.4, 1.8, 1.16 and 1.32 were prepared with concentrations of $100,50,25,12.5,6.25$ and $3.125 \mathrm{mg} / \mathrm{ml}$, respectively. In order to determine the antimicrobial effects of silver nanoparticles, $1 \mathrm{ml}$ of the stock solution with a concentration of $8000 \mu \mathrm{g} / \mathrm{ml}$ was used and dissolved in $1 \mathrm{ml}$ of deionized distilled water to achieve a 
concentration of $4000 \mu \mathrm{g} / \mathrm{ml}$. This serial dilution was repeated using deionized distilled water and dilutions of 2000, 1000, 500, 250, 125 and $62.5 \mu \mathrm{g} / \mathrm{ml}$ were achieved, respectively. Then, $80 \mu \mathrm{l}$ of each prepared dilutions were poured into the wells and incubation was done for $24 \mathrm{~h}$ at $37{ }^{\circ} \mathrm{C}$. After the incubation period, the diameter of inhibition zone was measured for each well $(10,11)$. First, for each bacteria according to the results obtained in the previous step, the concentration of the extract and silver nanoparticles with the lowest, average and highest bactericidal effects were selected and then these concentrations were combined in equal proportions. These compounds were applied on the four Gram-positive bacteria. There was an exception for Gram-negative bacteria ( $P$. aeruginosa) where according to the results of the previous step, concentrations of $50 \mathrm{mg} / \mathrm{ml}$ and $25 \mathrm{mg} / \mathrm{ml}$ were used as the average and lowest concentration of the extract, respectively. Rest of the cases were applied without any modification.

After preparing the medium for each bacteria and creating the wells, $80 \mu \mathrm{l}$ of each compound were poured into each well, and then incubation was done for 24 hours at 37 ${ }^{\circ} \mathrm{C}$. The growth inhibition zone of the plant extract and silver nanoparticles were measured and later compared. In order to compare the results, two-way analysis of variance (ANOVA) was used in SPSS-16 statistical software, and P-value of $<0.05$ was considered as the statistical significance level.

\section{RESULTS}

All the five concentrations prepared from the plant extract showed inhibitory effects against methicillin-resistant and -sensitive $\mathrm{S}$. aureus, $S$. epidermidis and $S$. pyogenes. Reducing the concentration of plant extract for all five tested bacteria significantly reduced the diameter of growth inhibition zone. The largest diameter of inhibition zone was observed in S. pyogenes. The inhibitory effects against bacteria were observed at all the concentrations prepared from the silver nanoparticles solution. The largest inhibition zone diameter was seen in the methicillinresistant $S$. aureus. In addition, reducing the concentration of silver nanoparticles significantly decreased the size of bacterial growth inhibition zone. In all types of combinations when the concentration of extract is the highest or average, its antibacterial effect against all five bacteria become reduced. When the lowest concentration of the plant is combined with the lowest concentration of the silver nanoparticles (combination 1), significant increase in the diameter of inhibition zone of $S$. pyogenes and $P$. aeruginosa was detected. Combining the lowest concentration of the extract and average concentration of the silver nanoparticles (combination 4) increased the inhibitory effects against $S$. aureus and $P$. aeruginosa. While, the combination of lowest concentration the extract and highest concentration of the silver nanoparticles (combination 7) significantly increased the inhibitory effect against $P$. aeruginosa only (Table 1). 
Table 1- Mean inhibition zone diameter (mm) for extract of Zataria multiflora and silver nanoparticles alone and combined, in the five tested bacteria

Extract of Zataria multiflora $\quad$ Silver nanoparticles

The combination of silver nanoparticles and extract of Zataria multiflora

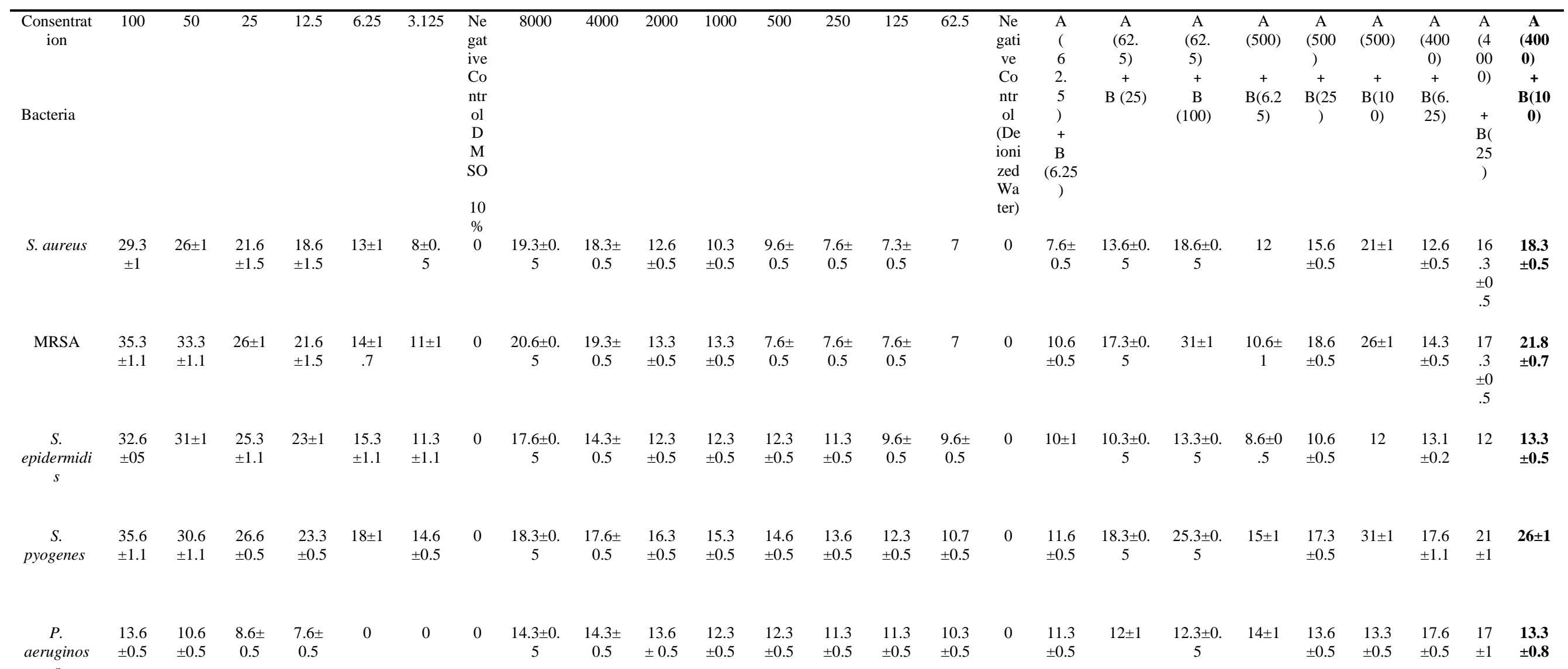




\section{DISCUSSION}

After the emergence and increase of bacterial resistance to antibiotics, many in vitro studies have been conducted to explore alternatives for antibiotics. The use of products that are generally regarded as safe (GRAS) have attracted considerable attention. Biologically active natural products derived from plants are among the most important GRAS substances, since these compounds obtained from the essential oils and plant extracts can be used in pharmaceutical industry as therapeutic agents against diseases and bacterial infections (12). According to the results of the present study, the antibacterial effect of Zataria multiflora is evident in different concentrations. Numerous studies have been done using the aqueous and alcoholic extracts and essential oil of thyme on Gram-positive and Gram-negative bacteria. In 2003, Sağdiç demonstrated the inhibitory effect of thyme essential oil against $E$. coli, $P$. aeruginosa and S. aureus (13). In 2010, Mahboubi study on the anti-staphylococcal properties of the Zataria multiflora plant showed the bactericidal properties of this plant, which is perfectly consistent with the result of the present study (14). Colloidal solutions of silver nanoparticles has attracted a lot of attention due to their antimicrobial properties and wide range of pharmaceutical, medical, veterinary medicine and food industry applications. Moyer (1960) used 5\% silver nitrate to treat burns and showed the antibacterial properties of this solution against E. coli, S. aureus and P. aeruginosa (15). After the emergence of antibiotic-resistant bacteria and restriction of the use of antibiotics, Furno et al. (2004) regarded nanosilver effective against many bacterial and fungal diseases (16). In 2010, Chaloupka et al. also indicated silver nanoparticles as one of the most effective metallic nanoparticles due to their multiple antimicrobial function (17). In this study, all five tested bacteria had growth inhibition zone at various concentrations of silver nanoparticles. According to the obtained results, $P$. aeruginosa shows more resistance to the inhibitory and bactericidal effects of silver nanoparticles compared to Grampositive bacteria. This is probably due to the different structure of bacterial wall in Gramnegative and Gram-positive bacteria. Purine in these bacteria uptakes and releases metals to the outer membrane and the periplasmic space.
The absorbed metals can bind to the functional groups (including groups of carbonate, phosphate and amine) and in this way they are entered less into the cell or react with the membrane-proteins (enzymes with sulfhydryl groups) (18). According to the results of this study, in combination of the lowest concentration of silver nanoparticles and plant extract, the diameter of growth inhibition zone for all bacteria was reduced, except for $S$. pyogenes in which the inhibition zone diameter was increased. Moreover, in the combination of the average concentration of silver nanoparticles and the lowest inhibitory concentration of the plant extract, only the growth inhibition zone of $S$. aureus and $P$. aeruginosa increased, while it was decreased in the case of other tested bacteria. In the combination of the lowest concentration of the extract with the highest concentration of silver nanoparticles, an increase was observed in the diameter of inhibition zone for $P$. aeruginosa. In the rest of the combinations, the diameter of the inhibition zone decreased for all bacteria. The use of high concentrations of the plant extract in combination with silver nanoparticles reduces the antibacterial effects, probably because of the disturbed stability and accumulation of silver nanoparticles. Small size is one of the most important characteristics of colloidal particles, and the antimicrobial properties of these particles are attributed to this characteristic. Metallic nanoparticles are unstable and accumulate in large masses and this accumulation leads to the loss of colloidal properties of these metallic particles. Chemical methods such as reduction of transition metal salts are the most convenient ways to control the size of particles (19). Plant compounds such as carbohydrates, flavonoids and terpenoids can also cause reduction of silver nanoparticles (20, 21). Anthocyanins and flavonoids are among the main factors involved in the biologic reduction of silver nanoparticles (21). Other sources also reported that phenolic groups or molecules, alkaloids and sugars are responsible for the biological reduction of metallic nanoparticles $(20,22)$. Zataria multiflora plant is rich in flavonoids, terpenoids and tannins. Moreover, GC/MS experiments indicated that phenolic compounds such as monoterpenes are one of the major constituents of this plant (23). 
Phenol derivatives such as thymol and carvacrol are the main compounds in the plant and the antimicrobial properties of this plant are also attributed to them $(23,24)$. Therefore, it seems when the combination takes place, the plant extract is place next to the prepared silver nanoparticles. Phenolic compounds, flavonoids and anthocyanins cause the reduction of silver nanoparticles, disrupt the particles' stability and reduce its effects. Moreover, since the plant components are in reaction with the silver nanoparticles, thus cannot function as antimicrobial agents.

\section{CONCLUSION}

Using the combination of high concentrations of plant extract and silver nanoparticles reduces the antimicrobial effects. However, when the

\section{REFERENCES}

1. Lowy FD. Antimicrobial resistance: the example of Staphylococcus aureus. Journal of Clinical Investigation. 2003; 111(9): 1265-74.

2. Kohno S, Yamaguchi K, Aikawa N, Sumiyama Y, Odagiri S, Aoki N, et al. Linezolid versus vancomycin for the treatment of infections caused by methicillin resistant Staphylococcus aureus in Japan. Journal of antimicrobial chemotherapy. 2007; 60(6): 1361-9.

3. Yassien M, Khardori N. Interaction between biofilms formed by Staphylococcus epidermidis and quinolones. Diagnostic microbiology and infectious disease. 2001; 40(3): 79-89.

4 .Cunningham MW. Pathogenesis of group A streptococcal infections. Clinical Microbiology Reviews. 2000; 13(3): 470-511.

5. Döring G, Pier GB. Vaccines and immunotherapy against Pseudomonas aeruginosa. Vaccine. 2008; 26(8): 1011-24.

6. Michel-Briand Y, Baysse C. The pyocins of Pseudomonas aeruginosa. Biochimie. 2002; 84(5): 499510

7. Lioyd JR. Microbial reduction of metals and radionuclides. FEMS microbiology reviews. 2003; 27(23):411-25. doi:10.1016/S0168-6445(03)00044-5.

8. Marambio-Jones $\mathrm{C}$, Hoek EMV. A review of the antibacterial effects of silver nanomaterials and potential implications for human health and the environment. Journal of Nanoparticle Research. 2010; 12(5): 1531-51.

9. Shafiee A, Javidnia K. Composition of essential oil of Zataria multiflora. Planta medica. 1997; 63(4): 371-2.

10. Forbes BA, Sahm DF, Weissfeld AS, Trevino EA. Methods for testing antimicrobial effectiveness. In: Bailey and Scott's Diagnostic Microbiology. (Eds EJ Baron, LR. Peterson and SM. Finegold), Mosby Co: St Louis, Missouri, 1990; 171-94. lowest concentration of the plant extract with antibacterial effect is used in the combination, the diameter of growth inhibition zone increases, which is different depending on the type of bacteria. However, further investigations in this regard are necessary for conclusions that are more accurate.

\section{ACKNOWLEDGMENT}

This article was derived from Shirin Sheikholeslami's thesis (No. 29) in completion of MSc course in Microbiology with supervision of Dr. Hamid Reza Ahmadi Ashtiani, Dr. Seyyed Reza Hosseini Doust and Dr Seyyed Mehdi Rezayat, at Islamic Azad University, Branch of pharmaceutical Sciences, Tehran, in 2012.

\section{CONFLICTS OF INTEREST}

Therer are no conflicts of interest.

11. Mahon C, Manoselis G. Textbook of Diagnostic Microbiology. chapter 3. WB Saunders Company; 2003.

12. Jobling J. Essential oils: a new idea for post harvest disease control. Good Fruit Veg Mag. 2000;11:50.

13. Sağdıç O. Sensitivity of four pathogenic bacteria to Turkish thyme and oregano hydrosols. LWT-Food Science and Technology. 2003; 36(5): 467-73. doi:10.1016/S0023-6438(03)00037-9

14. Mahboubi M, Ghazian Bidgoli F. Antistaphylococcal activity of Zatariamultiflora essential oil and its synergy with vancomycin. Phytomedicine. 2010; 17(7): 548-50. doi: 10.1016/j.phymed.2009.11.004.

15. Moyer CA, Brentano L, Gravens DL, Margraf HW, Monafo WW. Treatment of large human burns with $0.5 \%$ silver nitrate solution. Archives of surgery. 1965; 90(6):

812-67.

doi:10.1001/archsurg.1965.01320120014002.

16. Furno F, Morley KS, Wong B, Sharp BL, Arnold PL, Howdle SM, et al. Silver nanoparticles and polymeric medical devices: a new approach to prevention of infection? Journal of antimicrobial chemotherapy. 2004; 54(6): 1019-24. doi: 10.1093/jac/dkh478.

17. Chaloupka K, Malam Y, Seifalian AM. Nanosilver as a new generation of nanoproduct in biomedical applications. Trends in biotechnology. 2010; 28(11): 580-8.

18. Landkamer L, Honeyman B, Figueroa L, Dodge C, Francis A. Effects of cell structure and environmental parameters on sorption of heavy metals to bacteria: An experimental and modeling study. National meetingamerican chemical society division of environmental chemistry; 2000: ACS; 1996.

19. Ott LS, Finke RG. Transition-metal nanocluster stabilization for catalysis: a critical review of ranking methods and putative stabilizers. Coordination chemistry reviews. 2007; 251(9): 1075-100. 
20. Amin M, Anwar F, Janjua MRSA, Iqbal MA, Rashid U. Green Synthesis of Silver Nanoparticles through Reduction with Solanum xanthocarpum L. Berry Extract: Characterization, Antimicrobial and Urease Inhibitory Activities against Helicobacter pylori. International Journal of Molecular Sciences. 2012; 13(8): 9923-41. doi: 10.3390/ijms13089923.

21. Pavani K, Swati T, Snehika V, Sravya K, Sirisha M. Phytofabrication of load nanoparticles using grape skin extract. International Journal of Engineering Science. $2012 ; 4$.

22. Vigneshwaran N, Ashtaputre NM, Varadarajan PV, Nachane RP, Paralikar KM. Balasubramanya RH.
Biological synthesis of silver nanoparticles using the fungus Aspergillus flavus. Materials Letters. 2007; 61(6): 1413-8.

23. Sharififar F, Mirtajadini M, Azampour MJ, Zamani E. Essential oil and methanolic extract of Zataria multiflora Boiss with anticholinesterase effect. Pakistan journal of biological sciences: PJBS. 2012; 15(1): 49-53.

24. Saei-Dehkordi SS, Tajik H, Moradi M, KhalighiSigaroodi F. Chemical composition of essential oils in Zataria multiflora Boiss. from different parts of Iran and their radical scavenging and antimicrobial activity. Food and Chemical Toxicology. 2010; 48(6): 1562-7. doi: 10.1016/j.fct.2010.03.025. 